\title{
Persuading consumers: The use of conditional constructions in British hotel websites
}

Discourse \& Communication 2018, Vol. 12(6) 587-607 (C) The Author(s) 2018

Article reuse guidelines: sagepub.com/journals-permissions DOI: $10.1|77 /| 75048|3| 8805169$ journals.sagepub.com/home/dcm

@SAGE

\author{
Miguel Fuster-Márquez
}

IULMA, Universitat de València, España

\section{Carmen Gregori-Signes}

IULMA, Universitat de València, España

\begin{abstract}
Hotel websites display textual and non-textual strategies with the aim of turning online visitors into customers. This article focuses on two related textual aspects: how consumers are discursively construed and how conditional constructions are used in order to persuade and convince consumers of the adequacy of the hotel. The framework adopted for the analysis combines Stern's notion of 'implied consumer' with a corpus-driven approach. The corpus data comprises I 4 British hotel websites and totals half a million words. This is a subcorpus of COMETVAL, a database compiled at the University of València. The results reveal the importance of a number of words that address consumers directly or indirectly. These words intertwine with others to form patterns that help establish a bond between hoteliers and their clients. Further exploration of the corpus confirmed that some conditional sequences such as if you and should you are used by advertisers to speculate about the needs and wishes of consumers that the hotel can fulfil for them. The analysis suggests that conditional structures are a distinctive discursive characteristic strongly associated with the dialogic nature of the discourse hotel websites.
\end{abstract}

\section{Keywords}

Advertising, British hotel websites, conditional constructions, corpus linguistics, implied consumer, promotional and non-promotional discourse, tourism

\footnotetext{
Corresponding author:

Miguel Fuster-Márquez, IULMA and Departamento de Filologia Inglesa y Alemana, Facultad de Filologia, Traducción y Comunicación, Universidad de Valencia, Avda Blasco Ibáñez 32, Valencia 460I0, España. Email: miguel.fuster@uv.es
} 


\section{Introduction}

Hotel websites, an example of promotional advertising discourse in tourism, display an array of textual and non-textual strategies whose overall purpose is to persuade website visitors to become customers. There are two primary aims to this study: first, to explore how the implied consumer is textually construed and addressed in the advertising copies of hotel websites; and, second, to assess the use of conditional constructions with the pronoun you as a discursive strategy to engage the implied consumer in a direct dialogue with the persona. The persona represents the hoteliers while the implied consumers are 'the imaginary message recipients to whom the advertiser addresses'. To our knowledge, these discourse strategies have not received sufficient attention in the literature on tourism advertising.

The framework adopted for the analysis combined Stern's (1994) revised model of communication, in particular, her notion of implied consumer, with a Corpus Assisted Discourse Approach (CADS) (cf. Baker, 2015; Partington et al., 2013). The study corpus comprises 114 British hotel websites (BHW) and totals half a million words. This is a subcorpus of COMETVAL, a database compiled at the University of València. COMETVAL contains samples of tourism discourses in three languages (French, Spanish and English). The total number of words in this database is 7 million words.

The analysis was both quantitative and qualitative. The results revealed that there are a variety of words used to refer to the implied consumer, among which the pronoun you had an unusually high frequency, in particular in bigrams such as if you. A comparison with a larger reference corpus, the British English 2006 (BE06), confirmed that conditional constructions constitute a significant discursive characteristic strongly associated with the interpersonal dialogic nature of the discourse of hotel websites. One of the main functions of conditionals is to engage potential clients in considering a series of hypothetical situations in which the hotel gives instructions, specifies requirements and informs on products and services that can satisfy their customers' needs and wishes.

This article has been organised as follows. First, there is an overview of the literature on hotel websites and their relevance in the discourse of tourism. This is followed by a description of the corpus data and the methodology applied in the quantitative and qualitative analyses. We then explore how clients are textually constructed and how conditionals contribute to establish a dialogue between clients and hoteliers. Special attention is paid to the description of the bigrams if you and should you. Finally, the conclusion summarises some of the most relevant points of this research.

\section{Hotel websites, tourism and advertising}

A recent report published by the World Tourism Organisation (2014) suggests that Internet users visit an average of ' 14 different travel-related sites with about three visits per site, and carry out nine-related searches on search engines' (p. 6) before making their final choice regarding accommodation. Buhalis and Hyun Jun (2011) define $e$-hospitality as the use that hotels make of the Internet as a marketing distribution channel. They highlight two crucial advantages of $e$-hospitality for hotel promotion. First, that the Internet ensures hoteliers a global presence that enables both individual customers and the travel trade to 
access accurate information while providing easy, efficient, inexpensive and reliable ways of making and confirming reservations. Second, that hoteliers can make use of carefully designed websites to guide the onlooker's attention (cf. Nekić, 2015: 35-36). However, as Buhalis and Hyun Jun (2011) underscored, hoteliers no longer exert full control of the information about their hotel. Nowadays, social networks, online travel agents, review websites (e.g. TripAdvisor, Twitter) and previous customers have become an active element in the advertising process itself (cf. Buhalis and Hyun Jun, 2011: 28) and are powerful alternative sources of information about the quality of hotels. Nevertheless, as suggested in Qi et al.'s (2013) study, the individual hotel website, the object of study of this article, is still a popular channel for information and reservation purposes.

Like many other tourism text-types, hotel websites can be classified as an example of advertising, whose primary aim is to persuade potential consumers to purchase products and services (see Bhatia, 2005; Friestad and Wright, 1994; Ham et al., 2015; Nelson and Ham, 2012). In this regard, websites are crucial marketing channels designed to build interpersonal relations with potential clients by interpreting their preferences and needs. With this purpose in mind, hotels organise their websites into different viewing areas that foreground or background carefully selected features (Calvi, 2016; Cho, 2015; Dann, 1996; Huang, 2008; Manganari et al., 2012; Montoya-Weiss et al., 2003; Nekić, 2015), whose purpose is to attract the highest possible number of customers. Texts within hotel websites can be classified as either promotional or non-promotional, each text type being strategically allocated in different parts of the website. Non-promotional texts 'deal with legal issues concerning the rights and obligations of the service providers and customers' (Fuster-Márquez and Pennock-Speck, 2015: 55) and come under headings such as terms and conditions, privacy policy or cancellation (policies). These texts occupy the marginal areas of websites, and are usually long and devoid of multimedia support. Promotional texts, on the other hand, are core features of a hotel website and include, among others, details of accommodation, offers, access to a reservation system, photo galleries, information about complementary services, locations and attractions of the area and often reviews of previous customers. This distinction between promotional and non-promotional texts has bearings on our ensuing discussion of the role of consumers and the discourse meanings of conditionals in the BHW.

\section{Data and procedure}

A corpus of 490,899 words, found on $114 \mathrm{BHW}$, is the data source of this study. The data were gathered between 2012 and 2014, and are a part of COMETVAL, a database compiled at the University of Valencia which contains a sample of over 7 million words of public and private tourism websites in Spanish, English and French.

The framework adopted for the analysis is a Corpus Assisted Discourse Approach, often referred to in the literature as CADS (cf. Baker, 2015; Partington et al., 2013). In a recent contribution, Baker and McEnery (2015) advocate for such an approach, highlighting that corpus linguistics offers a powerful methodology for the analysis of discourse, allowing researchers to identify regularities in large collections of texts. Many researchers have stressed that a major advantage of a corpus methodology is that it helps to detect typical discourse patterns, showing the preferences not of individuals, not of particular 
texts, but of whole communities of practice (cf. Baker et al., 2008; Gabrielatos and Baker, 2008; Hyland, 2009; Partington et al., 2013; Stubbs, 1996). In this article, discourse is understood as a series of 'recurrent phrases and conventional ways of talking, which circulate in the social world, and which form a constellation of repeated meanings' (Stubbs, 1996: 158), since it has been observed that 'different text-types are repetitive in different ways and to different extents' (Stubbs and Barth, 2003: 62). Therefore, text-types can be distinguished by their preferences for individual words, sequences and/or grammatical constructions which reveal the existence of discourse choices.

Research within a CADS approach usually requires the compilation of ad hoc corpora, which is explored using techniques developed within corpus linguistics. These techniques have been found to be particularly useful when large amounts of data need to be explored, since they help to uncover meanings and patterns not evident to the 'naked-eye perusal' (Partington et al., 2013: 11). Furthermore, CADS is comparative in essence and combines quantitative and qualitative methods. The qualitative analysis usually pays attention to concordances and is strengthened with quantitative methods, such as those provided by the observation of word frequencies, keyword or ngram analysis. As Hunston (2011) asserts, there are compelling arguments in favour of combining quantitative and qualitative approaches. In her view, '[i]t would be inaccurate to see the qualitative and quantitative traditions as opposed to each other or as mutually exclusive' (Hunston, 2011: 50).

As Neumann (2003) highlights, 'the specific properties of a given register only become visible when compared to a mixture of other registers serving as a tertium comparationis' (p. 86). In the present analysis, features of the BHW corpus were compared with the same ones in the British English 2006 (BE06) corpus. The BE06, compiled by Baker (2009) contains 1,147,097 words of contemporary written British English. Its architecture is based on the design of the Brown Corpus (i.e. 2000 word samples from 500 website texts). The BE06 is composed of a mixture of written registers of selected samples of contemporary British English; most of the texts were produced between 2005 and 2007. The BE06 was accessed through the CQP Web (UCREL), whereas the BHW was processed with AntConc 3.5.0, a toolkit for corpus analysis designed by Laurence Anthony (2017). When comparing the two corpora, both absolute and relative (normalised) frequencies, as well as distribution (range of hotel websites) were taken into account.

The first step of the analysis was to extract and examine all the words that referred to potential clients (e.g. guests, customers, users). A corpus-driven approach was followed in order to decide which lexical items and ngram(s) were particularly relevant (Biber, 2009: 196). The most striking result to emerge from the data was the high frequency of the pronoun you, notably as part of the bigram if you. Consequently, we decided to examine in detail the discourse function of conditionals in the BHW.

The framework for the analysis of 'customer' words drew on the categories described by Stern $(1994,1996)$ in her model of communication, which was originally developed for the analysis of advertising. It was complemented with insights from Hyland's $(2001,2005$ a) research on interpersonal communication. Regarding the classification and meaning of conditionals, a variety of sources were consulted: English grammars (Biber et al., 1999; Halliday and Mathiessen, 2014; Huddleston and Pullum, 
2002; Quirk et al., 1985, etc.) together with specific research on conditional constructions in English (Dancygier, 1998; Gabrielatos, 2010, 2013; Simpson, 2001). In varying degrees, these works have offered valuable observations for the syntactic, semantic and pragmatic interpretation of conditionals in the 'imaginary' dialogue between hoteliers and customers in the BHW.

\section{The notion of implied consumer (Stern 1994-1996)}

Following the principles of social constructionism and Systemic Functional linguistic (SFL) traditions, Hyland (2005b) claims 'that all language use is related to specific social, cultural and institutional contexts' (p. 174). SFL conceives language as accomplishing three metafunctions: ideational, interpersonal and textual (cf. Halliday and Matthiessen, 2014). The interpersonal function focuses on how we enact our personal and social relationships through language with the people around us: '[i]nterpersonally, a text is a series of exchanges between speaker and addressee - even if it is a one-sided monologue that is essentially a series of statements acknowledged silently by the addressee' (cf. Halliday and Matthiessen, 2014: 45). Hyland's conception of metadiscourse (cf. Hyland, 2005a, 2005b; Hyland and Jiang, 2016) may be seen as a development of the interpersonal metafunction described in SFL. In Hyland's model, engagement is reader-oriented and brings readers into discourse. Engagement is explicitly marked by the textual presence of readers in discourse by means of questions, reader pronouns, directives, appeals to shared knowledge and personal asides. However, as argued by Degaetano and Teich (2011) 'there is no comprehensive or uniform picture of the lexicogrammatical expression of interpersonal meaning and our understanding of it remains fairly fragmentary' (p. 57).

Hyland's development of engagement in discourse shares strong affinities with Stern's model. Stern's (1994) multidimensional model of advertising, conceptually indebted to Bakhtin (1981), is adequate to understand how interpersonal communication between hoteliers and potential consumers is enacted on hotel websites. As illustrated in Figure 1, the model describes three types of participants in the complex interactional process of advertising communication (the sponsor, the author and the persona), and three multidimensional levels (source, commercial message and consumers) (Stern, 1994: 10). The advertisers or sponsors are the market representatives who exert control over the author; that is, the person/s who compose/s the message. Stern maintains that, whereas the sponsor and the authors are 'without-text-real-life figures', the persona and the implied consumer reside within the textual world (in this case the hotel website). This distinction is 'essential to capture the interactivity of the communicative intercourse between advertisers and consumers' (Stern, 1994: 5). The sponsorial consumers are the advertisers themselves who grant approval before the message is presented. The actual consumers are the individuals in the real world who comprise the target audience at which advertising aims and 'respond to the message in real-time by means of seeking information or making a purchase' (cf. Miles, 2007). Finally, the implied consumers 'are the imaginary message recipients whom the persona addresses' (Stern, 1994: 10). While the implied consumers represent hotel clients, the persona represents the hotelier(s), the staff and even the building itself (in this article we use of the holistic forms the hotel or the hotelier to refer to 


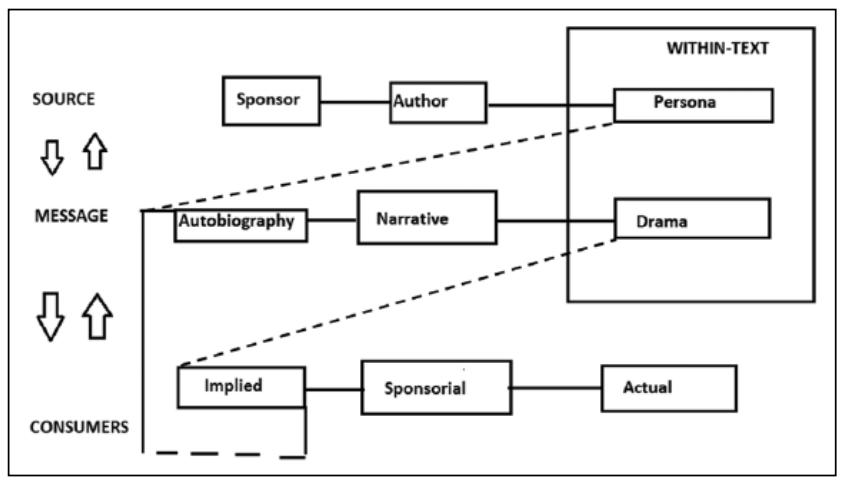

Figure I. Adapted from Stern's (1994: 9) Advertising Model.

the persona). Due to space constraints, it is not possible to discuss in detail all the multidimensional interactive sources and roles played by the various types of recipients (cf. Stern, 1994) in the process of creation and reception of the hotel's advertising copy. This article seeks to examine some of the strategies used to establish a dialogue between the persona and the implied consumer, on the hotel websites in the BHW corpus, by exploring the frequency and patterns of the lexical items that refer to potential hotel clients.

\section{Analysis and discussion}

\section{The implied consumer in BHW}

The first step in the analysis was to obtain a list of key terms in the BHW. For the calculations, we relied on the log-likelihood algorithm (hereafter LL), and, in addition, effect size (log's ratio) was implemented $(p<0.01)$. The BE06 was used as the reference corpus for this purpose. ${ }^{1}$ The resulting top 10 key items are listed in Table 1.

Table 1 includes the top 10 keywords obtained from the exploration of the BHW, that is, the words that occur in the target corpus, the BHW, with a greater frequency than expected when compared with a (usually) larger corpus (the BR06, in this case) (Baker, 2004; Scott, 1997). The comparison between the BHW and the Br06 showed that, in effect, some of the top keywords refer to consumers, namely your, you and guests. While words like you, your or please may also be frequent in other kinds of advertising, others such as hotel, room(s), guests are clearly associated with the discourse of tourism and hotel promotional discourse. Apart from those, the BHW contains a group of words that refer to hotel customers, namely person (352), client (164), visitors (145), customer (140), delegates (112), user (99), groups (85), traveller (58), arrivals (20) and golfers (8).

These results indicate that the way in which hotel clients are referred to varies according to context and purpose. Sometimes the hotelier addresses implied consumers as individuals (person) or as part of a group/s, while it establishes differences between two types of consumers, depending on the purpose of their visit: business (delegates) or leisure (visitors, golfers); other times, consumers are named in relation to management 
Table I. Top keywords in BHW.

\begin{tabular}{llll}
\hline Rank & Frequency & LL & Word \\
\hline 1 & 3698 & 7252.85 & hotel \\
2 & 4675 & 5221.18 & your \\
3 & 3077 & 4859.94 & room \\
4 & 4455 & 4702.23 & our \\
5 & 1661 & 3314.54 & rooms \\
6 & 1168 & 2491.19 & suite \\
7 & 5141 & 2431.12 & or \\
8 & 1217 & 2075.14 & please \\
9 & 5861 & 2071.36 & you \\
10 & 921 & 1885.06 & guests \\
\hline
\end{tabular}

BHW: British hotel websites; LL: log-likelihood algorithm.

deals (arrivals) or as online users. It is to be noted that in all of the above cases, the implied consumer is indirectly addressed in the third person. In what follows, we discuss in detail the reasons behind such lexical choices. In this regard, a distinction should be made between word forms and lemmas. Word forms, listed in Table 1, represent real instances of words in texts, and are given in italics, while lemmas (the singulars and plurals of each noun which represent the same word taken together) will be conventionally represented by small caps.

The lemma ARRIVAL (446) usually indicates date or time of arrival when used in the singular. However, the plural arrivals (20 cases), can be used metaphorically to refer to hotel clients, as in 'Morning arrivals are also possible, with advance notification'. The highly frequent PERSON (417) appears as a part of the pattern '[Quantity] + per person', for the purpose of informing potential clients about prices, as in 'Freshly brewed Tea and Coffee $£ 5.25$ per person'. The lemma GROUP (382) often collocates with the words 'accommodation', 'reservation' and 'booking(s)'; e.g. 'Agent commission is payable after the Event or final day of Group Accommodation'. DELEGATE (195) accompanies references to quantities (occupancy, rates), as in 'Rates start from $£ 150$ per delegate and include all of the above day delegate package'. VISITOR (192) usually refers to tourists in the area, for example, 'The International Sports Village is an excellent option for visitors looking for a holiday experience that is anything but ordinary'. Finally, TRAVE(L)LER (107) appears in combinations such as 'business traveller(s)' 'traveller review(s)' and others, for example, 'We may also record details on joint travellers, including their names and frequent flyer numbers, and the age of the driver of the rental car'.

In addition, the nouns customer, client, guests and user are also keywords in the BHW. These items deserve to be analysed in detail, together with the top keywords your, you. All of them seem to play an important role in the textual dialogue established between the persona and the implied consumers. Their frequency is illustrated in Figure 2. Absolute frequencies have been normalised per million to allow comparisons with BE06.

Figure 2 shows that the six words used to refer to the implied consumer have higher frequencies than those same words in the BE06. Very prominently, you and your have the 


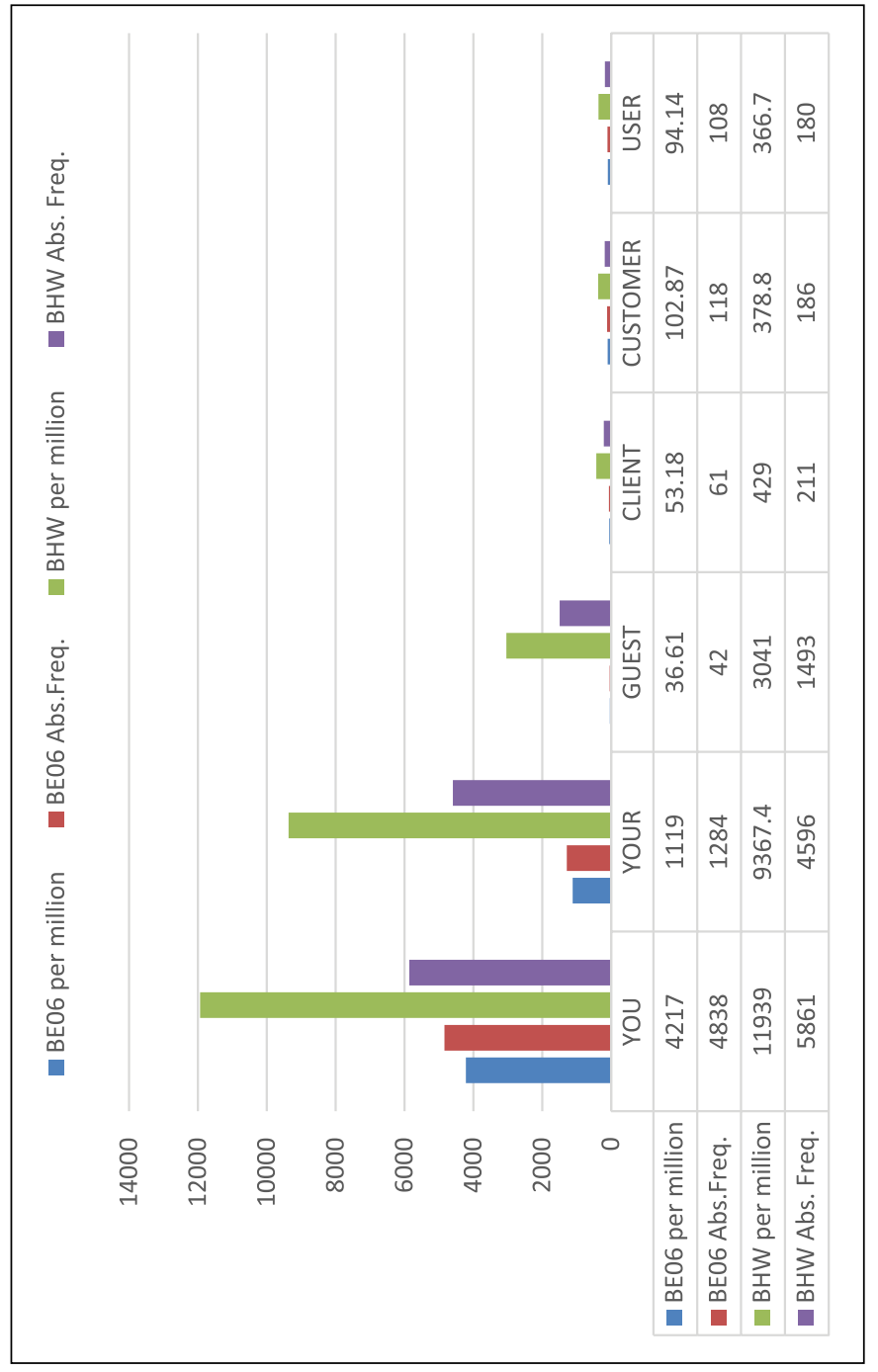

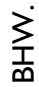


highest absolute frequencies, followed by GUEST and more distantly by CLIENT, CUSTOMER and USER.

Words such as client or customer are common in e-commerce; however, the case of GUEST appears to be more idiosyncratic; it is more significantly associated with hotel accommodation. The words user, customer and guest are often a part of nominalised sequences which have a referential function in the BHW. The word customer is frequently found in the compound customer service, and user is found in collocations such as user agreement or user information. Guest is found in sequences related to accommodation, such as guest house, guest bedroom, or to hotel policies, as in guest privacy policy. Furthermore, there are other discursive differences between the lemmas GUEST, CLIENT, CUSTOMER and USER.

On average, the lemma GUEST is used 13 times per site. As observed in (1), its use corresponds to a conventionalised, euphemistic and polite way of referring to customers staying in a hotel, since, in other contexts, guests would not pay for their stay:

(1) Guests enjoy the comfort and convenience of In-Suite Check-In, while we also provide twicedaily housekeeping, and round-the-clock concierge service, room service and laundry service.

While GUEST is typically encountered in promotional texts, the other lemmas (CLIENT, CUSTOMER and USER) are regularly confined to the non-promotional sections in the BHW, such as 'privacy policy', terms and conditions', 'cancellations' documents, where a number of obligations and liabilities are stated. These texts are often perceived as the negative side of the contract. In this context, the word CLIENT seems to retain a predominantly agentive role. Example (2) has been taken from the description of a hotel's cancellation policy:

(2) Where any client cancels any wedding, special event, private dinner or dance after they have had written confirmation allowing them to change their date then full cancellation charges will apply as per the original date of booking.

Similarly, user(s) is typically encountered in non-promotional texts to inform potential customers about the implications derived from using the hotel's online services, as illustrated in (3):

(3) By accessing this site, users agree to comply with these terms and conditions of use.

Special attention has been paid in our analysis to your and you, the top 'implied consumer' keywords in the BHW. The concordance plot tool in AntConc, which allows researchers to view the location of words in corpus texts, shows that you is very evenly distributed, found in practically all the websites (113 out of 114 in BHW) in both promotional and non-promotional sections. On average, you has 49 occurrences per website, whereas your (present in 108 websites) amounts to no less than 42 occurrences per site. The personal pronoun you appears occasionally in combination with customer, as in (4):

(4) You the Customer are strongly advised to read the terms and conditions as set out hereunder prior to completing this Reservation process. 
As indicated by Stern (1996: 92), the recurrent presence of you shows that 'advertising [...] is mimetic of personal dialogue ('I' or 'we' talking to 'you')'. First-person pronouns, Hyland (2005b) has argued, are an example, in academic discourse, of an explicit reader-pronoun rhetorical strategy used by writers to involve readers. In sharp contrast to this usage in academic writing, first-person plural pronouns on hotel websites do not function to engage customers; they invariably refer to the hoteliers' persona, that is, the within-the-text advertiser in the advertising copy, as illustrated in example (5).

(5) We offer special deals if you use our club as a party venue.

Regarding second-person pronouns, Cheng (2016: 93) noted that you is often used to 'establish a higher degree of interactivity with reader involvement, creating a sense of hospitality'; Cruz et al. (2017) find a similar use of the second-person personal pronoun in online brand messages such as Facebook; while Breeze (2015) reports that you is common in the editorial section of British newspapers, where ' $[t]$ he writer stages a high degree of intimacy with the reader, blurring the boundaries between the public and the private sphere' (p. 42). Likewise, Vaičenonienè (2006: 50) notes that its use is particularly pervasive in English advertising.

One has to be cautious, however, when assigning meanings and functions to words in isolation, since out-of-context conflicting interpretations are possible. It is only when words are examined with their co-text, by means of corpus techniques such as collocations, ngrams and concordancing, particularly when exploring large amounts of data, that the potential ambiguity can be reduced (Hunston, 2011: 14; Teubert, 2004: 83). In what follows, we analyse in detail the contexts in which you has been found.

The results obtained by means of the ngram technique, which yields uninterrupted word sequences in a corpus ranked by frequency, show that if you is the 10th most frequent bigram in the BHW corpus. The ngram tool in AntConc was applied setting as parameters sequences of two to four words; establishing a minimum cut-off frequency of 20 cases, and a minimum range of 20 in the entire corpus. The resulting top 10 sequences are shown in Table 2

Table 2. Top ngrams in British Hotel Websites (BHW).

\begin{tabular}{llll}
\hline Rank & Freq. & Range & Ngram \\
\hline 1 & 2543 & 107 & of the \\
2 & 1997 & 110 & in the \\
3 & 1679 & 105 & at the \\
4 & 1427 & 105 & to the \\
5 & 1102 & 85 & the hotel \\
6 & 1100 & 107 & on the \\
7 & 799 & 85 & will be \\
8 & 757 & 100 & from the \\
9 & 746 & 94 & for the \\
10 & 738 & 91 & if you \\
\hline
\end{tabular}


Remarkably, most sequences in Table 2 are bigrams containing a preposition followed by the definite article; in all probability, these are part of longer sequences that can introduce referential or informative meaning. However, two bigrams that may potentially host interpersonal functions are the hotel and will be. The sequence will be is often found in passive constructions where either the persona or the implied consumer function as the grammatical subjects. As for the sequence the hotel, it can be either purely referential as in (6), where it indicates location, or interpersonal, as in (7), where it represents the persona:

(6) We provide a mail and messaging service as well to ensure you receive your business messages and correspondence while you're at the hotel.

(7) The hotel reserves the right to make an appropriate charge to guests for deep cleaning of rooms.

Finally, the bigram, if you, ranked in the 10th position, is the first one that unequivocally relates to the implied consumer. This bigram is present in no less than 91 websites in the BHW, and is the only top sequence that hosts an explicit interpersonal function. These results called for a further exploration of conditionals in the BHW.

\section{Conditional constructions in the BHW}

Johnson-Laird and Byrne (2002: 646) consider conditional reasoning as 'a central part of thinking' (cf. Rescher, 2007: 1). This may explain why conditionals have been discussed in different disciplines, such as philosophy (see Rescher, 2007) and psychology (cf. Fugard et al., 2011; Johnson-Laird and Byrne, 2002). In-depth linguistic treatments of conditionals include, among others, Traugott (1986), Dancygier (1998) and Declerk and Reed (2001). Gabrielatos (2010: 13, 204) provides an overview of conditional typologies in English and discusses overlaps among typologies, while Akatsuka (1986) argues in favour of analysing conditionals by considering discourse context and the speaker's attitude. In his research on discursive features of advertising, Simpson (2001) draws on pragmatics and systemic-functional linguistics in order to distinguish between 'tickle' and 'reason' advertisements. Whereas 'tickle' ads appeal to humour, emotions and mood, 'reason' ads suggest reasons or motives for purchasing products (Simpson, 2001: 589). Drawing on Bernstein's (1974) work, Simpson (2001: 590) regards purposive and causal constructions as 'the bedrock of reason texts' in the advertising copy.

According to Halliday and Matthiessen (2014: 476), complex clauses of cause, reason, time and manner, '[enhance]' the meaning of another by qualifying it [in various ways]' and establish a cause-effect relationship between propositions. Johnson-Laird and Byrne (2002) find that '[c] onditionals have an indefinite number of meanings (...) and [indicate] a variety of relations between antecedent and consequent' (p. 674). In this regard, Gabrielatos (2010: 2) highlighted the lack of consensus among linguists 'as to the number or nature of types of conditionals'. Halliday and Matthiessen (2014: 477) place conditional clauses within enhancement 
categories; they list 'if' together with the sequences 'in the event of', 'provided that', and 'as long as' among the main markers of condition. All of these, they claim, are used to indicate positive condition 'if $\mathrm{P}$ then $\mathrm{Q}$ '. By contrast, the conjunctions 'unless', 'but for', and 'without' are markers of negative condition.

According to Huddleston and Pullum (2002: 738), prototypical conditional constructions have three components: if, plus a subordinate clause functioning as its complement (the protasis), and a matrix clause (the apodosis), as illustrated in example (8) from the BHW:

(8) If you are a student, please do not send any personal information about yourself to us.

In (8), the marker if is complemented by the protasis, 'you are a student', (together they form the 'conditional adjunct'). This is followed by the apodosis in the matrix clause, 'please do not send any personal information about yourself to us'. The subordinate clause in (8) expresses the condition, whereas the matrix clause is employed to formulate a recommendation, by means of a directive preceded by please. Nevertheless, conditional constructions can contain more than one protasis or more than one apodosis (extended by means of coordination), as shown in (9). Moreover, the order of constituents may be reversed, as in (10). Both examples are from the BHW:

(9) If you have any requests concerning your personal information or any queries with regard to the capture, storage and use of personal information please contact Marketing.

(10) Their superb and experienced crew will liaise with you on the day and leave you with an emergency contact number in case you need us once you're up and running.

A variety of conditional constructions with you as the subject of the protasis (representing the implied consumer) were found in the BHW. Table 3 provides a list of the most frequent key-cluster conditional constructions obtained from the comparison between the BE06 and the BHW. The keyness calculation was obtained using Rayson's 'log-likelihood and effect-size calculator' (available online at http://ucrel.lancs.ac.uk/ llwizard.html).

As for the types of conditionals, we distinguished between conditional constructions as such, marked by the presence of if, should, in the event of/that, provided that, unless, in case, and conditional-concessive constructions, marked by the presence of whether and even if. Among them, the absolute frequency of if you tokens was higher than that of all the other conditionals taken together.

As observed in Table 3, with the exception of the key-clusters if you, whether you and should you, which show the highest token frequencies, the frequencies of the remaining clusters is quite low, their presence being confined to a few hotel websites. In what follows, we offer a brief description of how these conditional markers are used in the BHW and then focus on the description of the three most frequent patterns. 
Table 3. Conditional-you sequences in British hotel websites.

\begin{tabular}{lcllr}
\hline Tokens & Range & Sequence & $\begin{array}{l}\text { Construction/ } \\
\text { function }\end{array}$ & Keyness \\
\hline 738 & 91 & $\begin{array}{l}\text { if you } \\
\text { whether you }\end{array}$ & $\begin{array}{l}\text { Conditional } \\
\text { Conditional- }\end{array}$ & 542.81 \\
94 & 43 & Concessive & 146.69 \\
51 & 30 & should you & Conditional & 85.17 \\
10 & 7 & in the event (of/that) you & Conditional & 24.10 \\
7 & 7 & provided that/you & Conditional & 8.76 \\
14 & 8 & unless you & Conditional & 4.26 \\
5 & 5 & even if you & Conditional- & 1.75 \\
3 & 3 & Concessive & Conditional & 1.05 \\
\hline
\end{tabular}

Quirk et al. (1985: 1091) and Halliday and Matthiessen (2014: 323) suggest that sequences containing the complex preposition in the event of may express a contingency relationship. For Halliday and Matthiessen (2014: 323), the phrases in the event of and in case have the sense of 'if'. Quirk et al. (1985: 1097) suggest that these conditional subordinators are used in indirect conditions of the open type (cf. Huddleston and Pullum, 2002: 739) and describe open conditions as neutral, given that 'they leave unresolved the question of the fulfilment or nonfulfillment of the conditions, and hence also the truth of the proposition expressed by the matrix clause'. In their view, the uncertainty of the condition expressed by in the event and in case introduces 'a tentativeness which adds politeness' to the utterance (Quirk et al., 1985: 1097). In (11), hoteliers warn customers of the negative consequences of failing to pay incidental charges; in (12) hoteliers supply an emergency phone number:

(11) Such charges will be payable by you on departure and, in the event that you fail to pay any such incidental charges, it is a condition of your contract (...).

(12) Their superb and experienced crew will liaise with you on the day and leave you with an emergency contact number in case you need us once you're up and running.

Halliday and Matthiessen (2014: 477) classify unless as a negative conditional subordinator (cf. Quirk et al., 1985: 1093), while Huddleston and Pullum (2002: 755) claim that the meaning of unless is equivalent to 'except if' or 'in all circumstances except if' as shown in (13) from BHW here unless is used to introduce some possible negative consequences:

(13) We won't change your towels in the evening unless you ask us to do so during evening turndown service.

The few examples of provided you are located in non-promotional texts. In (14), the subordinate clause introduced by provided (meaning 'on condition that') establishes the necessary condition (to follow the Scottish Outdoor Access Code) that will make it possible for the guests to enjoy the experience of wild camping: 
(14) You can go wild camping in Scotland and enjoy a night under the stars-provided you follow the Scottish Outdoor Access Code.

As for the very few instances of even if you, these indicate concession. In (15), the hotelier indicates that the consumer can check in late and still remain 'eligible':

(15) By securing your online reservation with a credit card, you are eligible for our Reservations Guarantee even if you check in late (after 6:00 pm).

The marker whether has been classified as a concessive conditional subordinator, used with indirect questions (cf. Gabrielatos, 2010; Huddleston and Pullum, 2002). In the BHW, whether you, one of the most frequent conditional markers (94 instances), is a lexico-grammatical sequence which appears in patterns such as ' whether you + would like/want/are looking for $[. .]+$. or'; it is used to give choices, or describe alternative situations that may affect the implied consumer. In (16), the hotelier offers alternative leisure activities to the implied customers"

(16) Whether you are looking to simply relax and unwind with a gentle swim or sauna or workout in the gymnasium you will find the facilities invigorating and inviting.

In the following section, if you and should you, the two most central conditional constructions in the BHW are analysed in greater detail.

\section{'If you' and 'should you' conditionals in BHW}

In his research on the conditional constructions in the $\mathrm{BNC}$, a corpus of contemporary British English containing 100 million words ( $90 \%$ written, 10\% spoken), Gabrielatos (2010: 49) calculated that if-conditionals represented ' $80 \%$ of conditional constructions in written British English' (cf. Dancygier, 1998: 14). Consequently, this finding might explain why the frequency of if-conditionals is so high in the BHW. However, the key-cluster analysis confirmed that if you was an unusually frequent collocational feature of hotel websites when compared with the BE06. The frequency differences, 378.35 per million words in the BE06, and 1503.36 per million words in the BHW, and its statistical significance $(542,81)$ suggested that if you was a specific feature in the discourse of hotel websites that deserved greater attention.

In the BHW, if you is indisputably the most common expression used to convey conditions in a personal and direct way. This bigram accounts for more than $60 \%$ of all if conditionals (1227) and is present in 91 out of 104 texts ( 6.5 cases per site), both promotional and non-promotional. In terms of meaning, the protasis typically describes the consumers' hypothetical needs, concerns or wishes in realistic situations, while the apodosis states the solution provided by the hotelier, as illustrated in (17). Although syntactic variation is possible, most frequently the protasis precedes the apodosis:

(17) If you are a family of 4, The Publisher Suite sofa converts to a sofa bed, plus an additional fold-out bed can be included. 
Table 4. Phraseological patterns in the British hotel websites (BHW) protases.

\begin{tabular}{ll}
\hline Tokens & Most common if-you patterns \\
\hline 103 & if you have $(*)$ questions/requests/queries, etc. \\
80 & if you would/ 'd like/prefer \\
43 & if you wish \\
37 & if you do not \\
37 & if you want \\
35 & if you are/you 're interested in/looking for/planning/searching/seeking, etc. \\
18 & if you prefer \\
18 & if you require \\
16 & if you need \\
\hline
\end{tabular}

The quantitative and qualitative observation of the conditions established in the protasis reveals the existence of some interesting lexico semantic patterns. That is, the verbs that follow if you reveal the existence of semantic preferences that hinge on the idea of 'need' or 'wish' (e.g. prefer, require), as illustrated in Table 4.

In the BHW, the conditionals with if you typically follow a problem-solution pattern (Hoey, 1994). In the protasis, the implied consumer (you) is hypothetically introduced as someone in need of something that can be successfully provided or satisfied by the hotelier (persona), as shown in (18) and (19):

(18) If you wish to hire a car during your stay, please speak to our concierge team.

(19) (...) if you need access to your room before that time, please advise us at the time of booking and we will endeavour to have your room ready earlier.

The exploration of concordances suggests that if conditionals (also should conditionals) followed by a directive in the apodosis was a recurrent structure. Among other possible pragmatic functions, these directives should be interpreted as examples of suggestions rather than orders, since the presence of politeness markers such as 'please' or 'feel free to' help to mitigate any force of obligation that might be implied by the use of the imperative. Frequently, the apodosis provides an indirect solution, as in (18) and (19), in which the implied consumer is advised to contact the hotel staff.

Other examples of the if you pattern, however, could be interpreted as warnings. Example (20) appeared in a non-promotional text dealing with cancellation policies, where instructions and warnings were commonly found. In example (20) the hypothetical act carried out by the implied consumer (cancel after $4 \mathrm{pm}$ ) may have negative consequences (the hotel will penalise the client):

(20) If you wish to cancel, please do so by $4 \mathrm{pm}$, hotel local time, on the day of arrival to avoid cancellation penalties.

Regarding their meaning and pragmatic function, if you conditional constructions are used to negotiate the deontic rights of the implied consumer and the persona. The hotelier 
is granted the status of the 'epistemic authority concerning the matter under discussion' (cf. Nissi, 2016: 314) from which obligations, prohibitions and permissions stem (Huddleston and Pullum, 2002: 178). Needless to say that actual consumers may challenge such an authority based on their own knowledge, any information or evaluation gathered from the reviews provided by former customers (cf. Buhalis and Hyun Jun, 2011). Pragmatically, if you seems to function as a genuinely persuasive device by providing a degree of 'tentativeness' and politeness to the propositional content (cf. Quirk et al., 1985: 1097), thus helping to mitigate the imposition conveyed by the frequent presence of directives (cf. Biber et al., 1999: 821).

Finally, the second key type of conditional constructions in the BHW is should you, which amounts to 51 cases and is present in 30 hotel websites in promotional and nonpromotional sections. Although its frequency is much lower than that of the if you sequence described above, its overall frequency is in sharp contrast with the scarcity of occurrences in general English, as represented in the BE06, where only 7 cases were found.

Quirk et al. (1985: 1094) attribute the use of the inverted sequence 'should + subject' to literary style, in which should has 'little modal meaning of its own' (Huddleston and Pullum (2002: 187). In their corpus-based grammar, Biber et al. (1999) remark that the conditional pattern should you is relatively rare in contemporary English, being particularly related to 'more formal, expository registers' (p. 852). The bigram should you is more commonly found in the BHW in patterns such as should you wish (14 cases), should you require (9 cases) and should you have (7 cases). In these cases, should you is used to introduce hypothetical situations which seem to go beyond the scope of standard requirements. The compliance of those contributes to enhance the positive image of the hotel, as illustrated in (21):

(21) Should you wish to check in outside of our opening times, please do let us know so that we can organise check in with a member of our bar staff.

The pattern should you is also preferred in suggestions that may be considered as belonging to the realm of the private and the personal. In these cases, should you mitigates the act of intrusion of the hotel in the private domain of its clients (22):

(22) Should you wish to meet with friends before heading out for the evening why not arrange to meet in The Tempus Bar

As is the case with the bigram if you, some of the verbs that frequently combine with should you are 'wish', 'want' and 'have'. The choice between the two conditional patterns may be purely stylistic, since the should-conditional can be interpreted as a more formal or polite way of addressing the implied customer than the if-conditional. However, both if you and should you appear to perform a similar function in the BHW, that of reducing the illocutionary force of obligation present in advice, recommendations, instructions or warnings concerning what to do in some realistic or hypothetical situations. 
The main difference between if you and should you affects their distribution in the corpus: the bigram should you is more often found in non-promotional texts, as in (23) where a hotel warns their clients about the negative consequences of departing earlier:

(23) Should you choose to depart early, price is subject to change.

\section{Conclusion}

This article focused on the presence of the implied consumer (Stern, 1994) in a corpus of 114 British Hotel Websites, which amounted to approximately half a million words. The methodology for the analysis followed a CADS approach and used different corpus techniques available through the AntConc toolkit for the exploration of the corpus - namely frequency lists, keyword, ngram analysis, concordances and concordance plots. In order to clarify the meaning and function of the most recurrent patterns, we used the British English 2006 as a reference corpus of contemporary British English.

The analysis revealed certain choices used by hoteliers to refer to the implied consumer. The preference for one or another word to refer to customers was often associated with their discursive function. The euphemistic GUEST, for example, was often found in promotional texts, whereas the lemmas CUSTOMER, CLIENT and USER were more regularly found in non-promotional texts. Whereas promotional texts can be said to have a more persuasive nature, non-promotional texts mostly inform potential clients about requirements, cancellation policies, instructions and warnings.

Among the words used to address the implied consumer, the pronoun you emerged as the most frequent word used to interact with potential clients. While the words guest, customer, client and user refer to the client in the third person, you and your addressed the implied consumer directly. Vaičenoniene (2006) claimed that second-person pronouns are a widespread feature of English advertising, which serve the purpose of establishing a persuasive and direct dialogue with potential customers, by creating an atmosphere that shortens the social distance between speaker and addressee.

An important finding that emerged from applying a corpus-driven approach was the high frequency of the sequence if you (also a key cluster), which pointed to the presence of an explicit interpersonal metafunction that involved the implied consumer. The presence of if you in the study corpus was quite evenly distributed and pervasive. Practically all hotels showed instances of this usage, on an average of 6.5 per hotel website. A more detailed analysis indicated a less prominent use of other conditional constructions such as the conditional-concessive sequence whether you, typically used to introduce choices, and the fairly formal conditional should you.

The genuine conditional constructions if you and should you appeared in both promotional and non-promotional sections of the BHW, where they served the goal of engaging the implied consumer in direct dialogue with the persona (hoteliers) in a variety of possible situations. Most conditionals were interpreted as examples of problem-solution patterns: the protasis typically presented the implied consumer (you) with a hypothetical but realistic problem, often indicated by means of if you followed by a verb expressing 'need' or 'wish', and its object; in the apodosis, the hotel customarily offered a solution, a suggestion, an instruction or a warning. Quite frequently, the apodosis was realised by 
a directive, often mitigated by polite markers such as please. A pragmatic and discursive reason for relying on conditional constructions may be related to politeness, since conditional constructions contribute to soften the stronger sense of obligation conveyed by directives. In so doing, conditional constructions offer a convenient pattern - and are therefore a relevant discursive advertising strategy in hotel websites - whose function is to introduce and provide details of the hotels' products or services and engage potential customers (implied consumers) in direct dialogue with the hotel (the persona).

\section{Declaration of conflicting interests}

The author(s) declared no potential conflicts of interest with respect to the research, authorship and/or publication of this article.

\section{Funding}

The author(s) received no financial support for the research, authorship and/or publication of this article.

\section{Note}

1. We thank Paul Rayson (UCREL) for recommending us to give priority to Log-Likelihood, and supplement our calculation of keyword analysis with effect size (Log Ratio).

\section{References}

Akatsuka N (1986) Conditionals are discourse-bound. In: Traugott EC (ed.) On Conditionals. Cambridge: Cambridge University Press, pp. 333-352.

Anthony L (2017) AntConc (Version 3.5.0. Dev) [Computer Software]. Tokyo, Japan: Waseda University. Available at: http://www.laurenceanthony.net/

Baker P (2004) Querying keywords: Questions of difference, frequency, and sense in keywords analysis. Journal of English Linguistics 32(4): 346-359.

Baker P (2009) The BE06 corpus of British English and recent language change. International Journal of Corpus Linguistics 14(3): 312-337.

Baker P (2015) Introduction to the special issue. Discourse \& Communication 9(2): 143-147.

Baker P and McEnery T (eds) (2015) Corpora and Discourse Studies: Integrating Discourse and Corpora. London: Palgrave Macmillan.

Baker P, Gabrielatos C, Khosravinik M, et al. (2008) A useful methodological synergy? Combining critical discourse analysis and corpus linguistics to examine discourses of refugees and asylum seekers in the UK Press. Discourse \& Society 19(3): 273-306.

Bakhtin M (1981) The Dialogic Imagination: Four Essays. Austin, TX; London: University of Texas Press.

Bernstein D (1974) Creative Advertising. London: Longman.

Bhatia V (2005) Generic patterns in promotional discourse. In: Halmari H and Virtanen T (eds) Persuasion across Genres: A Linguistic Approach. Amsterdam; Philadelphia, PA: John Benjamins, pp. 213-225.

Biber D (2009) Corpus-based and corpus-driven analyses of language variation and Use. In: Heine B and Narrog H (eds) The Oxford Handbook of Linguistic Analysis. Oxford: Oxford University Press, pp. 193-224.

Biber D, Johansson S, Leech G, et al. (1999) Longman Grammar of Spoken and Written English. Harlow: Pearson Education. 
Breeze R (2015) 'Or so the government would have you believe': Uses of 'you' in Guardian editorials. Discourse, Context \& Media 10: 36-44.

Buhalis D and Hyun Jun S (2011) E-tourism. Contemporary Tourism Reviews. Available at: https://www.goodfellowpublishers.com/free_files/Contemporary-Tourism-Review-Etourism $-66769 \mathrm{a} 7 \mathrm{ed0935d0765318203b843a64d.pdf}$

Calvi MV (2016) Guías de viaje y turismo 2.0: Los borrosos confines de un género [The travel guide and tourism 2.0: The blurred boundaries of a genre]. Ibérica 31: 15-38.

Cheng FW (2016) Constructing hotel brands: A multimodal analysis of luxury hotel homepages. Ibérica 31: 83-108.

Cho YC (2015) Exploring factors that affect usefulness, ease of use, trust, and purchase intention in the online environment. International Journal of Management \& Information Systems 19(1): 21-36.

Cruz R, Leonhardt JM and Pezzuti T (2017) Second person pronouns enhance consumer involvement and brand attitude. Journal of Interactive Marketing 39: 104-116.

Dancygier B (1998) Conditionals and Prediction: Time, Knowledge and Causation in Conditional Constructions. Cambridge: Cambridge University Press.

Dann G (1996) The Language of Tourism: A Sociolinguistic Perspective. Wallingford: CAB International.

Declerk R and Reed S (2001) Conditionals: A Comprehensive Empirical Analysis. Berlin; New York: Mouton.

Degaetano S and Teich E (2011) The lexico-grammar of stance: An exploratory analysis of scientific texts. In: Proceedings of the workshop on beyond semantics: Corpus-based investigations of pragmatics and discourse phenomena (Bochumer Linguistische Arbeitsberichte (3)), Göttingen, 23-25 February, pp. 57-66. Bochum: Ruhr-Universität Bochum.

Friestad M and Wright P (1994) The persuasion knowledge model: How people cope with persuasion attempts. Journal of Consumer Research 21(1): 1-31.

Fugard AJB, Pfeifer N, Mayerhofer B, et al. (2011) How people interpret conditionals: Shifts toward the conditional event. Journal of Experimental Psychology: Learning, Memory, and Cognition 37(3): 635-648.

Fuster-Márquez M and Pennock-Speck B (2015) Target frames in British hotel websites. International Journal of English Studies 15(1): 51-69.

Gabrielatos C (2010) A corpus-based examination of English if-conditionals through the lens of modality: Nature and types. PhD Thesis, Lancaster University, Lancaster.

Gabrielatos C (2013) Using corpus analysis to compare the explanatory power of linguistic theories: A case study of the modal load in if-conditionals. In: Corpus linguistics, Lancaster, 23-26 July.

Gabrielatos C and Baker P (2008) Fleeing, sneaking, flooding: A corpus analysis of discursive constructions of refugees and asylum seekers in the UK Press, 1996-2005. Journal of English Linguistics 36(1): 5-38.

Halliday MAK and Matthiessen C (2014) An Introduction to Functional Grammar, 4th edn. London: Arnold Publishing.

Ham CD, Nelson MR and Das S (2015) How to measure persuasion knowledge. International Journal of Advertising 34(1): 17-53.

Hoey M (1994) Signalling in discourse: A functional analysis of a common discourse pattern in written and spoken English. In: Coulthard RM (ed.) Advances in Written Text Analysis. London: Routledge, pp. 26-45.

Huang E (2008) Use and gratification in e-consumers. Internet Research 18(4): 405-426.

Huddleston R and Pullum GK (2002) The Cambridge Grammar of the English Language. Cambridge: Cambridge University Press. 
Hunston S (2011) Corpus Approaches to Evaluation: Phraseology and Evaluative Language. New York; London: Routledge.

Hyland K (2001) Bringing in the reader: Addressee features in academic articles. Writing Communication 18: 549-574.

Hyland K (2005a) Metadiscourse: Exploring Interaction in Writing. London: Continuum International Publishing Group.

Hyland K (2005b) Stance and engagement: A model of interaction in academic discourse. Discourse Studies 7(2): 173-192.

Hyland K (2009) Corpus informed discourse analysis: The case of academic engagement. In: Charles M, Pecorari D and Hunston S (eds) Academic Writing: At the Interface of Corpus and Discourse. London: Continuum International Publishing Group, pp. 110-128.

Hyland K and Jiang K (2016) Change of attitude? A diachronic study of stance. Written Communication 33(3): 1-24.

Johnson-Laird PN and Byrne RMJ (2002) Conditionals: A theory of meaning, pragmatics, and inference. Psychological Review 109(4): 646-678.

Manganari E, Siomkos G and Vrechopoulos A (2012) Perceived consumer navigational control in travel websites. Journal of Hospitality \& Tourism Research 38(1): 3-22.

Miles C (2007) A cybernetic communication model for advertising. Marketing Theory 7(4): 307334.

Montoya-Weiss MM, Voss GB and Grewal D (2003) Determinants of online channel use and overall satisfaction with a relational, multichannel service provider. Journal of the Academy of Marketing Science 31(4): 448-458.

Nekić M (2015) Tourist Activities in Multimodal Texts: An Analysis of Croatian and Scottish Tourism Websites. Basingstoke: Palgrave Macmillan.

Nelson M and Ham C (2012) The reflective game: How target and agent persuasion knowledge influence advertising persuasion. In: Rodgers S and Thorson E (eds) Advertising Theory. New York: Routledge, pp. 174-188.

Neumann S (2003) Exploitation of an SFL-annotated multilingual register corpus. In: Proceedings of the 4th international workshop on linguistically interpreted corpora (LINC-03) (eds A Abeillé, S Hansen-Schirra and H Uszkoreit). Budapest, 13-14 April, pp. 85-92. Stroudsburg, PA: The Association for Computational Linguistics.

Nissi R (2016) Spelling out consequences: Conditional constructions as a means to resist proposals in organisational planning process. Discourse Studies 18(3): 311-329.

Partington A, Duguid A and Taylor C (2013) Patterns and Meanings in Discourse: Theory and Practice in Corpus-Assisted Discourse Studies (CADS). Amsterdam: John Benjamins.

Qi S, Law R and Buhalis D (2013) Who booked five-star hotels in Macau? A study of hotel guests' online booking intention. Journal of Hospitality and Tourism Management 20: 76-83.

Quirk R, Greenbaum S, Leech G, et al. (1985) A Comprehensive Grammar of the English Language. London: Longman.

Rescher N (2007) Conditionals. Cambridge, CA: The MIT Press.

Scott M (1997) PC analysis of key words - And key key words. System 25: 233-245.

Simpson P (2001) 'Reason' and 'tickle' as pragmatic constructs in the discourse of advertising. Journal of Pragmatics 33: 589-607.

Stern B (1994) A revised communication model for advertising: Multiple dimensions of the source, the message, and the recipient. Journal of Advertising 23(2): 5-15.

Stern B (1996) The company 'voice' and the advertising persona. In: Thorson E and Moore J (eds) Integrated Communication: Synergy of Persuasive Voices (Advertising and Consumer Psychology). Mahwah, NJ: Lawrence Erlbaum Associates, pp. 87-102. 
Stubbs M (1996) Text and Corpus Analysis: Computer-Assisted Studies of Language and Culture. Oxford: Blackwell.

Stubbs M and Barth I (2003) Using recurrent phrases as text-type discriminators: A quantitative method and some findings. Functions of Language 10(1): 61-104.

Teubert W (2004) Language and corpus linguistics. In: Halliday MAK, Teubert W, Yallop C, et al. (eds) Lexicology and Corpus Linguistics: An Introduction. London; New York: Continuum International Publishing Group, pp. 73-112.

Traugott EC (ed) (1986) On Conditionals. Cambridge: Cambridge University Press.

Vaičenonienè J (2006) The language of advertising: Analysis of English and Lithuanian advertising texts. Studies about Languages 9: 43-55.

World Tourism Organization (2014) Online Guest Reviews and Hotel Classification Systems: An Integrated Approach. Madrid: World Tourism Organization.

\section{Author biographies}

Miguel Fuster-Márquez is a Senior Lecturer of English at the Universitat de València and a member of the Interuniversity Institute of Applied Modern Languages (IULMA). He has published work on the application of corpus approaches in the fields of English lexicology, phraseology, discourse, language variation and change, teaching methodologies and TV advertising. Most recently, he has participated in projects related to the analysis of tourism discourse, where he has applied corpus methodologies and sentiment analysis.

Carmen Gregori-Signes is a Senior Lecturer of English at the Universitat de València and a member of the Interuniversity Institute of Applied Modern Languages (IULMA). Carmen's primary research interest lies in the field of corpus-based discourse analysis. Past and current research has focused predominantly on the analysis of television texts, both fictional and nonfictional, digital storytelling and learners' discourse. She has recently extended her research to include the language of tourism. 